\title{
INFLUÊNCIA DE UM VÓRTICE CICLÔNICO DE ALTOS NÍVEIS, NO REGIME DE CHUVAS EM NATAL - RN EM JUNHO DE 2013 (ESTUDO DE CASO)
}

\author{
Micejane da S. Costa ${ }^{1}$, Maitê D. L. Coutinho ${ }^{1}$, Thalyta S. dos Santos ${ }^{1}$, Ana Carla dos S. \\ Gomes $^{1}$, Allan R. Silva ${ }^{1}$, Fernando Moreira da Silva ${ }^{2}$ \\ ${ }^{1}$ Centro de Ciências Exatas e da Terra - CCET/PPGCC/UFRN \\ ${ }^{2}$ Programa de pós-graduação em Ciências Climáticas -PPGCC/UFRN \\ micejane@yahoo.com.br
}

\section{RESUMO}

Objetivo principal é prever, com alguma antecedência, as possibilidades de ocorrência das precipitações, bem como sua quantidade e intensidade em áreas urbanas. Com isso, permitir a preparação de medidas preventivas contra eventos extremos.

\section{SUMMARY}

Main objective is to predict with some anticipation, the possibilities of occurrence of precipitation as well as their quantity and intensity in urban areas. With that, permitting preparation of preventive measures against extreme events.

\section{INTRODUÇÃO}

Uma forma de se entender os mecanismos hidrológicos e buscar tomadas de decisões residem no uso de modelos numéricos. Neste trabalho, foi utilizado o modelo ETA para analisar um Vórtice Ciclônico de Altos Níveis (VCAN) com a presença da CJNEB em sua periferia (Costa, 2010), atuando fora de época no Nordeste Brasileiro (NEB). Foi escolhido o dia 22 de junho de 2013 por apresentar casos de alagamentos registrados na cidade de Natal/RN.

\section{MATERIAL E MÉTODO}

Utilizaram-se campos oriundos do modelo ETA/CPTEC, sendo analisados os campos de precipitação (mm), linhas de corrente e magnitude do vento nos níveis de 850,500 e $200 \mathrm{hPa}$ e imagens de satélite (GOES 12) nos espectros do infravermelho e vapor d'água para a região do NEB. O ETA é um modelo regional hidrostático, utiliza uma grade E de Arakawa (Arakawa e Lamb, 1977), trabalha com equações primitivas, obtidas a partir dos princípios: conservação do momento, da energia termodinâmica e de massa, incluindo equações da continuidade para o vapor d'água. Com resolução horizontal de 20 e $40 \mathrm{~km}$, ambas com 38 camadas na vertical, cobrindo praticamente toda a América do Sul. Os dados de precipitação foram disponibilizados pela Empresa de Pesquisa Agropecuária do Rio Grande do Norte (EMPARN). Para visualização dos resultados, utilizou-se o software Grads. Verificaram-se os principais aspectos de formação, desenvolvimento e deslocamento do VCAN associado à CJNEB, utilizando como dados de entrada a rodada do modelo ETA.

\section{RESULTADOS}

Analisando todos os campos sinóticos utilizados nesse estudo, foi possível verificar nas linhas de corrente em $200 \mathrm{hPa}$ (Figura 1a), a presença da Alta da Bolívia (AB), atuando sobre a região Norte do Brasil, com sua posição quase estacionaria. Esta $A B$ permitiu a formação de um 
VCAN próximo ou sobre o NEB. Essa posição favoreceu o VCAN, bem definido centrado em torno de $01{ }^{\circ} \mathrm{S} / 37^{\circ} \mathrm{W}$, com suas bordas atuando no continente. $\mathrm{O}$ alto índice de precipitação ocorrido no dia (22) em Natal-RN está associado à presença desse sistema. Em sua periferia, ocorre confluência em baixos níveis e difluência em altos níveis o que resulta em formação de nebulosidade e atividade convectiva, mesmo que de forma localizada, o que ocorreu em Natal (Figura 1).

Verifica-se um prolongamento da crista do Anticiclone Subtropical do Atlântico Sul (ASAS), centrado a leste de $25^{\circ} \mathrm{W}$, permitindo que na região NEB predomine um escoamento do ar de leste, o que aumenta a instabilidade na região (Figura 1b). Esse tipo de circulação provocou muita instabilidade pelo nordeste e norte da Região Nordeste do Brasil, onde o tempo ficou nublado com períodos intensos de chuva, principalmente no litoral e leste de PE, da PB e do $\mathrm{RN}$.

No decorrer do dia, foi possível verificar chuvas fortes localizadas, atingir algumas áreas do RN, principalmente a capital Natalense. A Figura 1c ilustra a distribuição da precipitação pluvial, onde o modelo ETA estimou $70 \mathrm{~mm}$ para a capital do Rio Grande do Norte. Sendo que para esse dia (22), segundo dados pluviométricos obtidos pela EMPARN, chegou a chover $95,5 \mathrm{~mm}$, o que da pra perceber que o modelo apesar de ter subestimado em $25,5 \mathrm{~mm}$ seu resultado, ele conseguiu captar bem a distribuição espacial da precipitação.

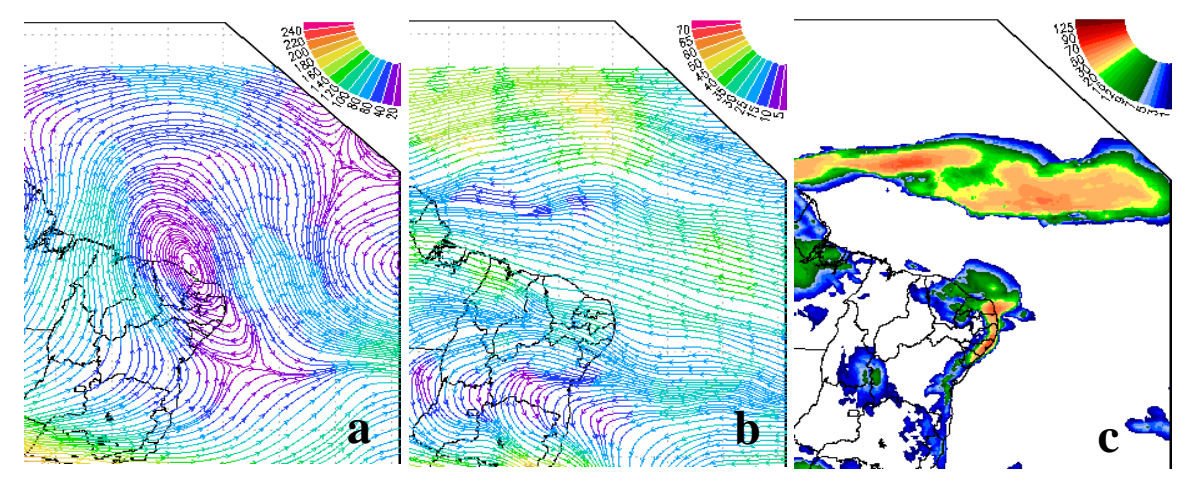

Figura 1 - Linhas de corrente em (a) 200 hPa (b) 850 hPa junho de 2013.

(c) Precipitação (mm), para o dia 22 de

Foram utilizados imagens de satélite GOES 12 (Figura 2a e 2b), no canal infravermelho (IR) e vapor d'água (WV) para identificar os tipos de nuvens associadas, e o grau de umidade. Observaram-se nuvens do tipo cumuliformes presentes em quase todo o NEB e oceano Atlântico Sul.
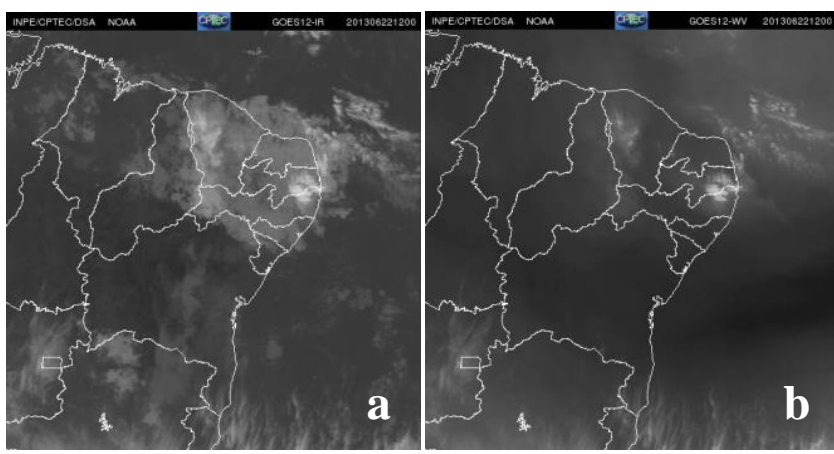

Figura 2 - Imagem de Satélite Goes 12, dia 22 de junho, 2013. (a) infravermelho; (b) vapor d'água. 
A chuva forte que caiu em Natal no dia 22 alagou ruas e abriu buracos na cidade (Figura 3). Como um bom exemplo, pode-se citar a rua Minas Novas que teve um alagamento que se estendeu até a rua Jerusalém, deixando moradores ilhados impossibilitados de sair de casa. Prejudicando comerciantes e moradores. Segundo a Emparn, choveu $95.5 \mathrm{~mm}$ na capital Potiguar nas últimas 24 horas.
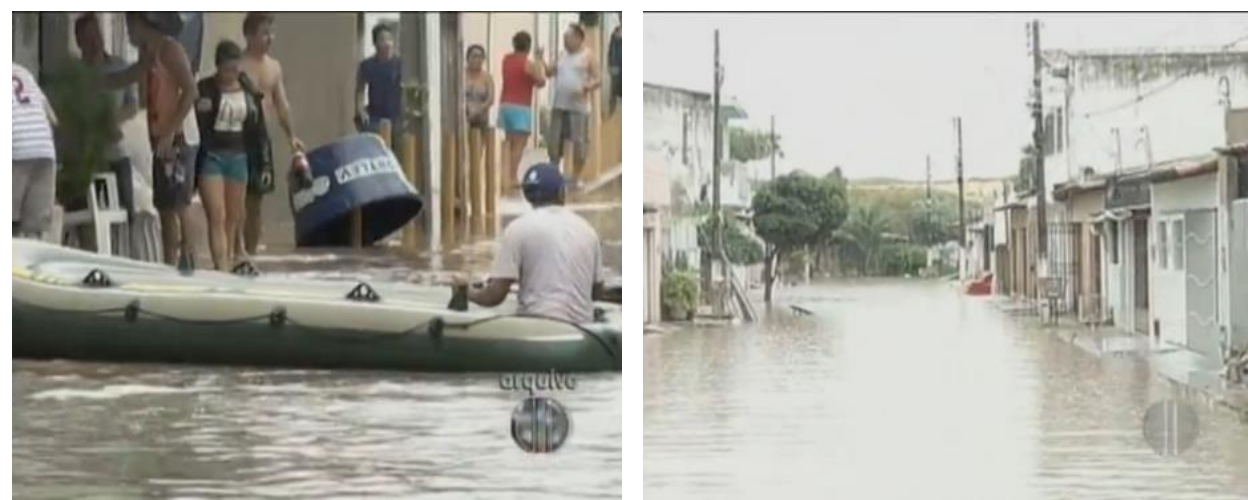

Figura 3 - Exemplos de transtornos à população nas ruas (a) Minas novas; (b) Jerusalém, bairro Neópolis - Natal-RN

\section{CONCLUSÕES}

Os campos de precipitação mostraram que é possível aumentar o grau de certeza e precisão na previsão, porém quanto ao aspecto quantitativo, no que traduz em condições de alagamentos na cidade de Natal, o modelo necessita de ajustes.

\section{REFERÊNCIAS}

ARAKAWA,A; LAMB, V. R. Computational Design of The Basic Dynamical Processes of the ucla General Circulation Model. Methods in computational physics. 17.Ed. Academic Press: 1977. P.173-265.

COSTA, M. S. Vórtice Ciclônico em Altos Níveis Associado à Corrente de Jato no Nordeste Brasileiro nos anos de 1998 - 2007. 2010. 113 F. Dissertação (Mestrado Em Meteorologia) Instituto de Ciências Atmosféricas (ICAT/UFAL), Maceió - Al. 